TABLE FI. Lallice dislances in A.†

\begin{tabular}{c|r|r|r|r|r}
\hline & \multicolumn{1}{c|}{$\mathrm{F}$} & $\mathrm{Cl}$ & $\mathrm{Br}$ & \multicolumn{1}{c|}{$\mathrm{I}$} & $\mathrm{ClO}$ \\
\hline & 2.452 & 2.773 & 2.886 & $(3.05)$ & 3.50 \\
$\mathrm{Ag}^{+} \frac{\mathrm{Ag}}{\mathrm{Na}}$ & +0.132 & -0.041 & -0.095 & -0.18 & -0.04 \\
& 2.320 & 2.814 & 2.981 & 3.231 & 3.5 \\
\hline
\end{tabular}

t All the values (see footnote to Table I) apply to sodium chloride structure, which $\mathrm{AgClO}$ and $\mathrm{NaClO}$, have at high temperatures above $155^{\circ}$ and $314^{\circ} \mathrm{C}$, respectively. (For the
indebted to Professor L. S. Ramsdell.)

of the silver ion, which does not possess the rare gas structure and the increasing polarizability from $\mathrm{F}^{-}$to $\mathrm{I}^{-}$. However, the difference $\mathrm{Ag}^{+}-\mathrm{Na}^{+}$for the perchlorates is also considerably more negative than that for the fluorides, in spite of the small polarizability of $\mathrm{ClO}_{1}{ }^{-}$and its greater separation from $\mathrm{Ag}^{+}$. This cannot be explained by "anion contact." Thus it appears that the larger distance in AgF compared with $\mathrm{NaF}$ is mainly due to the loosening effect of the small $\mathrm{F}^{-}$on the more easily polarizable $\mathrm{Ag}^{+}$. In cases where polarization effects can be neglected, one can consider the size of $\mathrm{Ag}^{+}$and $\mathrm{Na}^{+}$as nearly equal, or probably that of $\mathrm{Ag}^{+}$as a little larger.

${ }^{1}$ K. Fajans and G. Joos, Zeits. f. Physik 23, 1 (1924). Cf. the list of later papers, e.g., K. Fajans, Zeits. f. physik. Chemie B24, 103 (1934); A. Kruis, ibid. 34, 82 (1936).

$2 \mathrm{~K}$. Fajans, Naturwiss. 11, 165 (1923)

3 V. M. Goldschmidt, Norske Videns.-Akad. Oslo, No, 8, 72 (1927)

4 Concerning the hydrides, cf. E. Zintl and A. Harder, Zeits. f. physik. Chemie B 14, 265 (1931).

ph. K. Fajans and K. F. Herzfeld, Zeits. f. Physik 2, 317 (1920);

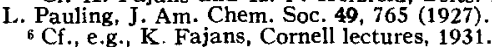

\section{Molar Volume, Refraction and Interionic Forces}

Kasimir Fajans

Depariment of Chemistry, University of Michigan, Ann Arbor, Michigan February 12, 1941

$\mathrm{T}$ HE data in the preceding letter show the important influence of the polarization of the ions on lattice distances and give a new support to the conclusions arrived at by the study of the deviations of molar refraction from additivity which were explained on the basis of the polarization (deformation) of the electronic systems.

Th. Neugebauert in a series of papers developed a wave mechanical theory of these influences. His conclusions agree in all respects with those derived from the experimental evidence and give a better theoretical understanding of the relations involved.

The view is generally accepted that when an anion and cation combine to form a molecule or crystal, their electronic systems interpenetrate each other. As is implied in the calculations of Neugebauer and clarified by very valuable discussions with Professor Roger H. Gillette, this interpenetration is equivalent to an introduction of a positive charge into the electronic system of the anion and of a negative charge into that of the cation.

From the above we can conclude that the addition of a cation to an anion leads to a diminution not only of the refraction (polarizability) of the anion but also to a contraction of its volume.

How large this effect can be is shown by the fact that the refraction of $\mathrm{I}^{-}$is $19.2 \mathrm{cc} /$ mole, that of $\mathrm{HI}$ is 13.7 $\mathrm{cc} / \mathrm{mole}$ and that the volume of these particles can, in first approximation, be assumed to be proportional to their refractions.

An increase of the size of a cation is to be expected when it combines with an anion.

In order to test whether the above expectations find confirmation also in the classical case of alkali halides, in Fig. $1 b^{*}$ are plotted the differences between the molar volumes of the solids and the apparent volumes of the salts in infinitely dilute solution. As the latter values are exactly additive within the experimental errors, the pronounced deviations from additivity revealed by Fig. 1b show clearly that they are due to the behavior of the volume of the solid salts. It is not possible to discuss the details in this short letter. It may only be emphasized that the general character of the deviations from additivity is the same as shown in the corresponding Fig. 1a by the molar refractions. Lithium iodide, in which we have to expect the strongest tightening of the anion, appears at the bottom of both figures; the fluorides, in which a loosening of the cation is expected, are at the top of the figures.

The regularities of the Figs. 1a and $1 \mathrm{~b}$ show some differences which are in part due to the much stronger influence of the ions on the volume of the solvent than on its refraction.

A similar figure resulted, in an investigation with Mr. Norman Bauer, by plotting the differences between the corresponding values of the molar dispersion of light, $\left(R_{D}-R_{\infty}\right)$, of the alkali halides. The relative deviations from additivity are, in the case of dispersion, generally stronger than for the refraction.

The deviations from additivity of the volumes of solid alkali halides shown by Fig. 1b were demonstrated long ago, ${ }^{2}$ but were not understood at that time, by the method used in the above letter in discussing lattice distances; e.g., the difference between the molar volumes of iodides and bromides increases from $7.88 \mathrm{cc}$ for lithium to $10.44 \mathrm{cc}$ for rubidium. However, the difference in lattice distances in this case diminishes from $0.262 \mathrm{~A}$ for the lithium salts to $0.227 \mathrm{~A}$ for the rubidium salts. The explanation of this apparent contradiction follows simply from mathematical properties of the differences of distinctly different numbers and differences between their cubes. For the hydrides and fluorides of $\mathrm{Li}$ to $\mathrm{Rb}$ both the differences in volume $\mathrm{e}^{3}$ and distance vary in the same direction due to the approximate equality of the corresponding values. So it is not necessarily an indication of the ions behaving as rigid spheres when the lattice distances sometimes do not show any appreciable deviations from additivity.

* See preceding letter.

1 Th. Neugebauer. Physik. Zeits. 94, 655 (1935); 99, 687 (1936); Hungarian Acad. Sci. 54, 337 (1936).

${ }^{2}$ K. Fajans and H. G. Grimm, Zeits. f. Physik 2, 299 (1920)

$3 \mathrm{Cf}$. Wilhelm Biltz, Raumchemie der festen Stoffe (Leopold Voss, Leipzig, 1934), p. 166. 